\title{
On Resultative Verb Compounds in Cantonese and Mandarin
}

\author{
Helena Yan Ping Lau ${ }^{1}$, and Sophia Yat Mei Lee ${ }^{2}$ \\ helena.lau@connect.polyu.hk;ym.lee@polyu.edu.hk \\ ${ }^{1,2}$ Department of Chinese and Bilingual Studies, The Hong Kong Polytechnic University
}

\begin{abstract}
This paper conducts a comparative study on the resultative verb compounds (RVCs) in Cantonese and Mandarin with an aim to reveal and explain the rules governing the use of RVCs in Cantonese. Mandarin RVCs are classified into six types in terms of the number, the sequence, and the event role of the argument(s). While Mandarin RVCs are found to be rather productive in expressing resultatives, there are syntactic constraints imposed on the use of RVC construction in Cantonese. Given that Mandarin RVCs are often restricted in Cantonese, three substitutive constructions that are used to form resultatives have been introduced, namely $\mathrm{V}$-dou 3 constructions, V-dou 3 in verb-copying construction, and causative construction formed with gaau2-dou3 'cause'. Factors that determine the corresponding structures used in Cantonese have been discussed. Claiming that the expressions of Cantonese resultatives should be highly associated with the event roles the involved NP arguments play, we demonstrate that such a classification of RVCs has contributed to the conclusion proposed in this paper. We also propose a set of linking rules which are designated for resultatives in Cantonese. It is hoped that this study sheds light on the syntax studies of Chinese.
\end{abstract}

Keywords: Resultative verb compound, V-de, V-dou3, causative construction, Cantonese, Mandarin Chinese

\section{Introduction}

Resultative verb compound (RVC) has been a well-ventilated topic in Modern Chinese linguistics due to its ubiquitous occurrence in Chinese especially Mandarin. A resultative verb compound in Chinese is composed of two elements, with the second element (V2) denoting the result of the action indicated by the first element (V1) (Thompson 1973; Lu 1977; Li and Thompson 1981; Shi 2002). Since 'V1' and 'V2' are widely used as the first and the second predicates of RVCs in previous work, these terms are adopted in this study. Thompson (1973) proposed the most general creating rule for RVCs:

(1) $\mathrm{V}_{\text {(action) }}+\mathrm{V}_{\text {(intransitive) }} \rightarrow[\mathrm{V}-\mathrm{V}] \mathrm{RV}_{\text {(action) }}$

As shown in (1), V2 should be an intransitive verb as proposed by Thompson (1973), Packard (2000: 95-96) ${ }^{1}$, however, suggests that the V1 of resultative verbs "represents in general the open set of Mandarin transitive verbs", and V2 is "a member of a class of usually

\footnotetext{
${ }^{1}$ In the work of Packard (2000), RVC is formed as $\left[\mathrm{V}_{2} \mathrm{~V}\right] \mathrm{v}$, in which V indicates the result of the action denoted by $\mathrm{V}_{2}$. Here, we use $\mathrm{V} 1$ and $\mathrm{V} 2$ to avoid confusion.
} 
non-transitive, often stative verbs that indicate the result...". In other words, the second element may not necessarily be intransitive. Consider (2):

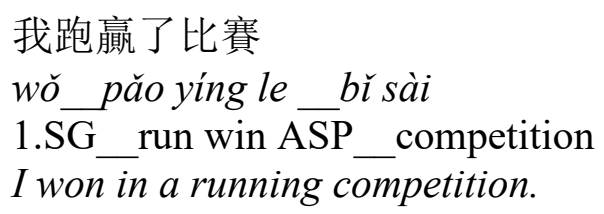

One may argue that V2 may take either one or two arguments when it is used independently, as in 我贏了 wo ying le 'I won'. Yet, Li (1990: 186) indicates that 贏 ying 'win' is in fact transitive as "it always has an internal theta-role to assign" even if the object is covert in the surface structure. This explains the reason why people are bound to ask "what did you win?". Apart from the transitivity of V1 and V2, some properties shared by RVCs have also been noted in the work of Thompson (1973) and Li and Thompson (1981). First, RVCs cannot be preceded by degree adverbs. Second, RVCs, unlike most verbs in Chinese, are incompatible with reduplication. Third, RVCs can occur in the potential form, meaning that the insertion of 得 de 'DE' or 不 $b u$ 'not' in between the two constituents is allowed. Fourth, other than potential infixes, elements such as aspect markers, measure words, etc. are not allowed to intervene between the two constituents.

In addition, there are several different kinds of results that can be expressed by an RVC, such as cause, achievement, direction and phase (Li and Thompson 1981). In this study, we only focus on the cause and achievement ones due to the infinite number of their combinations allowed in Chinese. In the following sections, the term ' $\mathrm{RVC}$ ' is used to denote RVCs of cause and achievement.

With regard to Chinese RVCs, numerous studies have examined them concerning the headedness. There are four approaches proposed: a) V1 being the head (Li 1990, 1995; Cheng and Huang 1994; Wang 2001), b) V2 being the head (Tai 2003), c) neither V1 nor V2 being the head (Huang and Lin 1992), and d) both V1 and V2 being the heads (Gu 1992). The formation of RVCs also intrigued many researchers. Li $(1990,1995)$ suggested that RVCs are formed in the lexicon. Gu (1992) further pointed out that they are occasionally formed in the lexicon through theta-identification. Huang (1992) proposed that they are derived syntactically. Cheng (1997) argued that the formation can neither be explained by using a pure lexical approach nor a pure syntactic approach.

While most previous studies on RVCs focus on Mandarin Chinese, little work has been done on investigating Cantonese RVCs. As one of the main varieties of Chinese, Cantonese seems to resemble Mandarin very closely. Cheng et al. (1997) compared the properties of verbal compounds in Cantonese, Mandarin, and Taiwanese, proposing that Cantonese and Mandarin are similarly formed in the lexicon, whereas Taiwanese is formed in the syntax. Chow (2012) investigated the interface between the semantic and syntactic realizations of RVCs in Mandarin and Cantonese, suggesting that most RVCs in Mandarin have parallel syntactic realizations with their corresponding Cantonese sentences. However, Lau and Lee (2015) argued that if RVCs in Mandarin and Cantonese do share the same structure in all cases, the prevailing use of ill-formed Cantonese RVCs produced by non-native speakers will be unexplained. They further pointed out that there are some noticeable differences between the two Chinese varieties in terms of the usage. Example (3) is taken from Lau and Lee (2015: 231) to show the difference in productivity between Mandarin and Cantonese RVCs, in which (a) is a well-formed Mandarin RVC, and (b) is a syntactically parallel yet ill-formed sentence of (a) in Cantonese. 
(3)
a. 我跑丟了車票
wǒ_ păo diū le_chē piào
1.SG_run lose ASP_ticket
I lost the ticket as I ran
b. *我跑跌咗張 車飛
ngo5 paau2 dit3 zo2 zoeng1_ce1 fei1

Since RVCs in Cantonese are found to be less productive than they are in Mandarin, most of the previous work has been dedicated to the study of Mandarin Chinese, neglecting numerous concerns regarding Cantonese RVCs. Williams (2014) acknowledged the methodological difficulty in conducting research on $\mathrm{RVCs}^{2}$ as crucial judgements of acceptability of RVCs are often delicate. Moreover, Williams (2014) also highlighted the importance of comparative work on RVCs which undoubtedly sheds light on some dimension of Universal Grammar.

This study aims to address the following questions: (1) under what conditions can Mandarin RVCs be realized using the same way in their Cantonese counterparts? (2) How is the same conceptual content encoded when Mandarin RVCs are not allowed in Cantonese?

This work is organized as follows. In Section 2, we briefly present the classification of Mandarin RVCs. RVCs are divided into six types in terms of the number, the sequence, and the event role of the argument(s). In Section 3 to 5, we introduce types of RVCs that contain one to three arguments, respectively. We examine different types of Mandarin RVCs and explore whether these Mandarin resultatives can be constructed in the same way in Cantonese. We also account for the expressions of the same conceptual content when there is no RVC counterpart in Cantonese. Section 6 turns to the factors that determine the corresponding structures used in Cantonese in forming the conceptual base of Mandarin RVCs. We then discuss how the classificatory framework has contributed to the conclusion proposed in this paper. Section 7 concludes with a summary reiterating the main contributions of this study.

\section{The classification of RVCs}

Of all the approaches to Mandarin RVCs, Chang (2003)'s theory of event roles is adopted. In this paper, we argue that Chang's (2003) theory of event roles is advantageous in helping us better capture the different between Cantonese and Mandarin. We prove that it is the event role, instead of thematic role, an argument plays in a resultative structure that determines how the argument is linked to the syntax. Therefore, Chang's (2003) theory of event role is selected among all the other approaches as the basic classification framework of the paper.

Drawing on the insight of Chang (2003), we classify Mandarin RVCs into six major types in terms of the number, the sequence, and the event role of the arguments. We follow Chang (2003) for the classification of Type 1 to Type 5. However, as Chang (2003) only dealt with RVCs that are in linear order (i.e. subject position being occupied by a logical subject of an RVC) and their passivizations, we propose to add a new type (i.e Type 6) for non-linear constructions (i.e. subject position not being occupied by a logical subject of an RVC). We discuss the properties of each type of RVCs based on the definitions of event roles given in Chang (2003). Before moving on to the properties of each type of RVCs, we first familiarize ourselves with different event roles that play a part in event structure. Given that a number of previous studies (van Voorst 1988; Dowty 1991; Tenny 1994; Chang 2001) suggested that

\footnotetext{
${ }^{2}$ RVCs are named as "Causal VVs" in Williams (2014).
} 


\section{Lau and Lee}

thematic roles are incapable of determining the syntactic positions of NP arguments, event roles are, instead, taken into account in this study to link the NP arguments to syntax. Following Croft (1998), Chang (2003) suggested that participants of an event are placed at the beginning or the endpoint of the event in the causal sequence. Three event roles that may involve in Chinese RVCs are initiator (i.e. entity involved in the initiation point), target of activity (i.e. entity undergoes an action) and locus of affect (i.e. entity involved in the endpoint). Different event roles may refer to the same entity in a single event, but their presence or absence depends on the Hierarchy of Event Roles proposed in Chang (2003: 335), as in (4).

(4) Hierarchy of Event Rules

Initiator $>$ Locus of affect $>$ Target of activity

Chang (2003) claimed that these event roles are different from the thematic roles proposed in O'Grady (1996) in terms of the syntactic positions of the NP arguments of RVCs. While thematic roles can occur in many positions in a sentence, event roles are linked to a specific position. Consider (5) and (6), in which (6) is taken from Lau and Lee (2015: 235).

(5) a. 他寫累了小說

tā xiě lèi le xiăo shuō

3. $\overline{\mathrm{SG}}$ write tired-ASP novel

He is tired for he has been writing novels.

b. Thematic Roles \& Event Roles

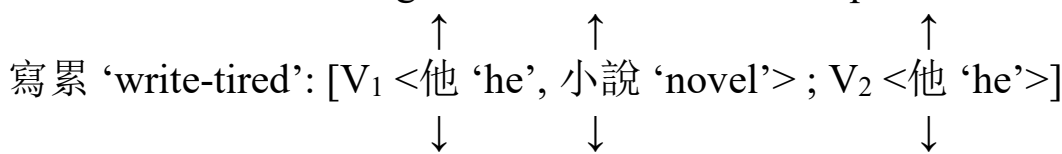

Event roles: Initiator Target of activity Locus of affect (covert)

c. BA construction

*他把小說寫累了

tā bă xiăo shuō xiě lèi le

3. $\overline{\mathrm{SG}}$ _BA_novel_write tired-ASP

d. Verb-copying construction

他寫小說寫累了

tā xiě xiăo shuō xiě lèi le

3.SG write novel write tired-ASP

He is tired for he has been writing novels.

(6) a. 他剪短了頭髮

tā_jiăn duăn le__tóu fà

3. SG_cut short ASP hair

He had a haircut.

b. Thematic Roles \& Event Roles

Thematic roles: Agent Theme Theme

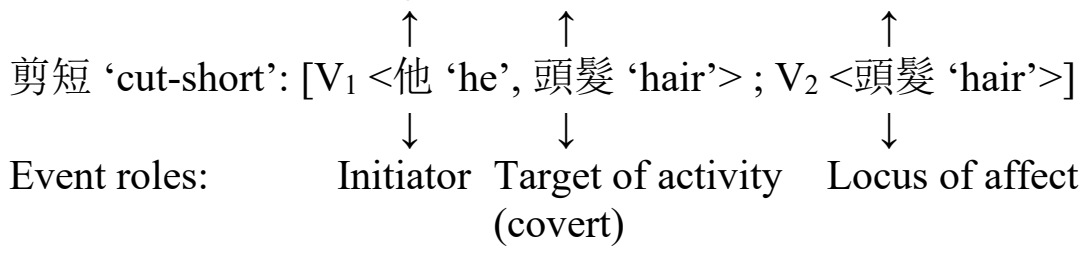


c. BA construction

他把頭髮剪短了

tā_bă_ tóu fà _ jiăn duăn le

3. $\overline{\mathrm{SG}}$ BA hair cut short-ASP

He cut his hair and his hair became short as a result.

d. Verb-copying construction

*他剪頭髮剪短了

tā_jiăn_ tóu fà_ jiăn duăn le

3. $\overline{\mathrm{SG}}$ _cut hair_cur short-ASP

Comparing the objects 小說 xiao shuo 'novel' and 頭髮 tou fa 'hair' in (5) to (6), although both of them play the thematic role of the theme ${ }^{3}$, only the one in (6) can take the position immediately following the word 把 $b a$ 'BA' to form a well-formed $b a$-construction as shown in (5c) and (5d). As for verb-copying construction, (5d) and (6d) show that only the one in (5) can take the position immediately following the first copied verb. However, the compatibility of $b a$-construction can be explained in terms of the event roles. When the object plays the role of the target of activity as in (5), it can form a grammatical verb-copying construction, with the object immediately following the first copied verb. When the object plays the role of both the target of activity and locus of affect as in (6), the role of target of activity is covert according to the Hierarchy of Event Roles. Therefore, the sentence in (6a) cannot be reconstructed in a verb-copying construction given that only the target of affect can take the position immediately following the first copied verb. The object, as a locus of affect, can only take the position following the word 把 $b a$ ' $\mathrm{BA}$ ' in a $b a$-construction. Therefore, it can be concluded that only event roles, instead of thematic roles, are capable of accounting for the syntactic differences among different Chinese RVCs.

In view of that, Chang (2003) further proposed a couple of linking rules to account for the position of each NP argument of Chinese RVCs. Linking Rule 1 suggests that the initiator role is linked to the subject position, while the locus of affect role is linked to the position immediately following V2 (Linking Rule 2). The locus of affect role may also take the position immediately following the word 把 $b a$ 'BA' in $b a$-constructions (Linking Rule 3 ). Linking Rule 4 suggests that the target of activity role is linked to the position immediately following a copied verb (i.e., the first V1) in verb-copying constructions. Regarding Linking Rule 5, Chang (2003:343) claimed that passivization is "an operation that re-structures the linking relations, permitting the locus of affect NP argument to occur as subject, and the initiator NP argument to appear in the periphery as object of bei or is omitted". In this paper, we will prove that it is the event role of an argument plays an important role in a resultative structure as it determines how the argument is linked to the syntax. We will also examine the applicability of these linking rules based on the Cantonese data, and propose a set of linking rules for Cantonese resultatives. However, as the 將 zoengl-construction is not as widely used as its Mandarin counterpart $b a$-construction as it is found to only appear in disposal cases and in very formal situations (Yang 2020), Linking Rule 3 will not be taken into account. As for the application of the Hierarchy of Event Roles, consider (7).

(7) 他跑累了

tā păo lèi le

3.SG_run tired ASP

He ran himself tired.

\footnotetext{
${ }^{3}$ We follow O'Grady et al. (1997:265-266) who use the term "theme" to refer to a recipient of an action that changes or does not change state.
} 
The RVC in (7) is composed of V1 跑 pao 'run' and V2 累 lei 'tired'. Each verb takes an NP argument, to which the same entity (i.e. 他 $t a$ 'he') is referred. The NP argument 他 $t a$ 'he' is the initiator and the locus of affect of the RVC. According to the Hierarchy of Event Roles, when two NP arguments are referring to the same entity but with different event roles as in (7), only the one with the higher role is syntactically overt. It is suggested that the initiator role is expressed, whereas the locus of affect role is suppressed. Therefore, the initiator occurs in the subject position, obeying Linking Rule 1. As for the explanations of other linking rules, examples will be given in the following sections.

\subsection{Type 1 RVCs}

In this paper, event role plays an important part in the classification of RVCs. Sentence (7) is a typical example of Type 1 RVCs. The V1 and V2 of a Type 1 RVC are intransitive. Each verb takes only one argument, as in 他跑了 ta pao le 'he ran ${ }^{4}$, and 他累了 ta lei le 'he is tired'. As the two verbs take an identical argument, 他 $t a$ 'he' plays the roles of the initiator and the locus of affect. When both event roles refer to the same entity, only the role in higher status is syntactically expressed. Thus, the initiator is linked to the subject position of the sentence.

\subsection{Type 2 RVCs}

Most V1 and V2 of a Type $2 \mathrm{RVC}$ are intransitive with each of them taking a different argument, and some are of a transitive V1 and an intransitive V2 with the logical object of V1 being covert in the resultative constructions. Regardless of the transitivity of V1, a Type 2 RVC takes two arguments in its syntactic structure, as in (8). In (8), 他 $t a$ 'he' is the subject NP of V1 哭 $k u$ 'cry' and 李四 'Lisi' is the subject NP of V2 煩 fan 'annoyed'. The RVC construction in (8) is composed of two parts, one is 他哭了 ta ku le 'he cried' which is the cause of the event denoted by the RVC and the other one is 李四煩了 Lisi fan le 'Lisi is annoyed' which is the result of the RVC. As an object phrase in the syntactic structure of (8), 李四 'Lisi' is defined as the logical subject of V2 as it was 李四 'Lisi' who felt annoyed but not 他 $t a$ 'he'. In other words, 李四 'Lisi' is the locus of affect who is involved in the resulting state, and that is the reason why 李四 'Lisi' can be defined as the subject NP of V2.

$$
\begin{aligned}
& \text { 他哭煩了李四 } \\
& \text { tā_ kū fán le_Lǔsì } \\
& \text { 3. } \overline{\mathrm{SG}} \text { _ry annoyed ASP_Lisi } \\
& \text { He cried and it made Lisifeel annoyed. }
\end{aligned}
$$

In (8), 他 ta 'he' plays the initiator role and 李四 'Lisi' plays the locus of affect role. Given that the two event roles denote two different entities, they are both realized in the syntactic structure. Obeying Linking Rules 1 and 2, the initiator role is placed in the subject position, and the locus of affect role follows the V2 immediately.

\footnotetext{
${ }^{4}$ According to Cheng and Sybesma (1998), 跑 pao 'run' may need a non-referential object 步 $b u$ 'step' in its unspecified object reading, but the dummy object is optional. They further pointed out that if the object is omitted, the verb shifts to ergativity and expresses the meaning of 'he ran away/ escaped'. However, 他跑了 ta pao le 'he ran' here is to show that the V1 of the RVC 跑累 pao lei 'run-tired' is subcategorized for one NP argument. It should not be interpreted as 'he ran away/escaped'.
} 


\subsection{Type 3 RVCs}

Type 3 is composed of a transitive V1 and an intransitive V2, in which V1 takes a subject NP and an object NP, and V2 only takes a subject NP. Example (6) is repeated here in (9):

(9) 他剪短了頭髮

tā_ jiăn duăn le_tóu fà

3. SG_cut short ASP_hair

He had a haircut.

In (9), the V1 剪 jian 'cut' takes two arguments as in 他剪頭髮 ta jian tou fa 'he had a haircut'. The subject NP of V1 他 $t a$ 'he' is the initiator, and the object NP of V1 頭髮 tou fa 'hair' is the target of activity. The V2 短 duan 'short' is intransitive, and it takes only one argument as in 頭髮短了 tou fa duan le 'hair is shortened'. The subject NP of V2 頭髮 tou fa 'hair' plays the locus of affect role. As the NP 頭髮 tou fa 'hair' plays two roles in the event denoted by the RVC 剪短 jian duan 'cut-short', the target of activity role is not overtly realized in the structure due to its lower status.

\subsection{Type 4 RVCs}

Chang (2003) proposed that a Type $4 \mathrm{RVC}$ is composed of a transitive V1 and an intransitive V2. However, we notice that V2 of a Type $4 \mathrm{RVC}$ is not necessarily intransitive. Consider (10) and (11), in which (10) is a duplicate of (5).

(10) 他寫累了小說

tā_xiě lèi le_xiăo shuō

3. $\overline{\mathrm{SG}}$ write tired-ASP novel

He is tired for he has been writing novels.

(11) 張三聽怕了這首歌

Zhāngsān_ tīng pà le_zhè shǒu gē

Zhangsan_listen sick of-ASP_this song

Zhangsan played this song for so many times that he is sick of it.

Both V1 in (10) and (11) are transitive, meaning that each of them takes a subject NP and an object NP. As for V2, the one in (10) is an intransitive one, while in (11) is a transitive one. In (10) and (11), the subjects 他 $t a$ 'he' and 張三 'Zhangsan' play both the initiator and the locus of affect role, and the objects 小說 xiao shuo 'novel' and 這首歌 zhe shou ge 'this song' play the target of activity role. The locus of affect roles of 他 ta 'he' in (10) and 張三 'Zhangsan' in (11) is not overtly expressed as 他 ta 'he' and 張三 'Zhangsan' at the same time play the initiator roles in (10) and (11). When an argument plays two roles at the same time, only the one with a higher status is overt. According to the Hierarchy of Event Roles, the locus of affect roles of both (10) and (11) are not overtly expressed in the syntactic structures as the initiator roles have a higher status in the hierarchy. Therefore, the event roles the subjects and objects played in (10) and (11) are the same, and the only difference between (10) and (11) lies in the transitivity of V2.

\subsection{Type 5 RVCs}

The two verbs of a Type 5 RVC take three arguments, and none of them are identical as shown in (12). V1 takes a subject NP 他 ta 'he' and an object NP 樹 shu 'tree' as in 他砍樹 ta kan 
$s h u$ 'he chopped down the tree', and V2 takes only a subject NP 斧子 $f u z i$ 'axe' as in 斧子㝴 了 fu zi duan le 'the axe was broken'.

(12) 他砍樹砍斷了斧子

tā_kăn_shù_ kăn duàn le__fŭ zí

3. $\overline{\mathrm{SG}} \_$chop_tree_chop broken ASP_axe

He broke the axe accidentally while chopping down trees.

In (12), the subject NP of V1 is 他 $t a$ 'he' and the object NP is 樹 $s h u$ 'tree'. The former plays the initiator role and the latter plays the target of activity role of the RVC. V2 only takes a subject NP (i.e. 斧子 $f u z i$ 'axe') which serves as the locus of affect role as it was broken in the resulting state after carrying out the action of V1. Since none of them are co-indexed, all of them are syntactically expressed. Different from other types, Type 5 RVCs appear in a verbcopying construction. That is, the V1 is copied and followed by the RVC. According to the Linking Rule 4 proposed by Chang (2003), if a target of activity role is to appear in the syntactic structure, it follows immediately the copied verb. Thus, 樹 shu 'tree' occupied the position after the copied verb.

\subsection{Type 6 RVCs}

In addition to the five abovementioned types, there is another type of RVCs which is overlooked in Chang (2003). In the current study, we name it Type 6. Type 6 is different from Type 1 to Type 5 in terms of the order of NP arguments, with the subject position not being occupied by the initiator. Consider (13) - (15), in which (14) is taken from Lau and Lee (2015: 234).

(13) 這部電影看哭了張三

zhè_ bù__diàn yǐng_ kàn kū le__Zhāngsān

this__CL_movie_watch cry $\overline{\mathrm{ASP}} \_$Z Zhangsan

Zhangsan was moved by the movie.

(14) 這首歌唱哭了觀眾

zhè_shǒu_gē_chàng kū le__guān zhòng

this_ CL__song__sing cry ASP_audience

The audiences were moved by the song.

(15) 那個夢哭醒了張三

nà__gè_mèng_ kū xǐng le__Zhāngsān

the_CL_dream_cry awake ASP_Zhangsan

He woke up in tears for the dream.

(13) - (15) shows that the subject and object position of Type 6 RVCs can be taken by arguments of different event roles. The subject 這部電影 zhe bu dian ying 'this movie' in (13) is the target of activity and 張三 'Zhangsan' is the initiator and the locus of affect of the RVC. As initiator has a higher status according to the Hierarchy of Event Role, the locus of affect role should be suppressed in the sentence. However, (13) demonstrates the violation of Linking Rule 1 but the sentence is still well-formed in Mandarin. It can be claimed that Type 6 RVCs in Mandarin do not obey the linking rules as Mandarin canonical sentences do. This claim is further supported by examples (14) and (15). The subject position of (14) is also taken by a target of activity (i.e. 這首歌 zhe shou ge 'this song'), but the object position is taken by the 
locus of affect (i.e. 觀眾 guan zhong 'audience') and the initiator is suppressed in the sentence. As for (15), the subject 那個夢 na ge meng 'the dream' is an independent cause ${ }^{5}$ that triggered the activity of 哭醒 ku xing ‘cry awake'. It is neither the logical object of V1 nor V2. The object position is taken by the initiator as well as the locus of affect (i.e. 張三 'Zhangsan').

\subsection{Summary}

In this Section, we have classified and discussed six types of Mandarin RVCs based on the event roles the NP arguments play in the resultative structures. The properties of each type of RVCs are as in Table 1:

\begin{tabular}{|c|c|c|c|c|}
\hline Type & $\begin{array}{l}\text { Event role } \\
\text { occupying the } \\
\text { subject } \\
\text { position }\end{array}$ & Argument(s) of each Verb & Event Roles & $\begin{array}{l}\text { No. of } \\
\text { arguments }\end{array}$ \\
\hline Type 1 & Initiator & $\begin{array}{l}\mathrm{NP}_{1}+\mathrm{V} 1 \\
\mathrm{NP}_{1}+\mathrm{V} 2\end{array}$ & $\begin{array}{l}\text { - } \mathrm{NP}_{1} \text { : Initiator } \\
\text { - } \mathrm{NP}_{1} \text { : Locus of affect } \\
\text { (covert) }\end{array}$ & 1 \\
\hline Type 2 & Initiator & $\begin{array}{l}\mathrm{NP}_{1}+\mathrm{V} 1 \\
\mathrm{NP}_{2}+\mathrm{V} 2\end{array}$ & $\begin{array}{ll}- & \mathrm{NP}_{1}: \text { Initiator } \\
\text { - } & \mathrm{NP}_{2}: \text { Locus of affect }\end{array}$ & 2 \\
\hline Type 3 & Initiator & $\begin{array}{l}\mathrm{NP}_{1}+\mathrm{V} 1+\mathrm{NP}_{2} \\
\mathrm{NP}_{2}+\mathrm{V} 2\end{array}$ & $\begin{array}{l}\text { - } \mathrm{NP}_{1} \text { : Initiator } \\
\text { - } \mathrm{NP}_{2} \text { : Target of activity } \\
\text { (covert) } \\
\text { - } \quad \mathrm{NP}_{2} \text { : Locus of affect }\end{array}$ & 2 \\
\hline Type 4 & Initiator & $\begin{array}{l}\text { a) } \mathrm{NP}_{1}+\mathrm{V} 1+\mathrm{NP}_{2} \\
\mathrm{NP}_{1}+\mathrm{V} 2 \\
\text { b) } \mathrm{NP}_{1}+\mathrm{V} 1+\mathrm{NP}_{2} \\
\mathrm{NP}_{1}+\mathrm{V} 2+\mathrm{NP}_{2} \\
\end{array}$ & $\begin{array}{l}-\mathrm{NP}_{1} \text { : Initiator } \\
\text { - } \mathrm{NP}_{2} \text { : Target of activity } \\
\text { - } \mathrm{NP}_{1} \text { : Locus of affect } \\
\text { (covert) }\end{array}$ & 2 \\
\hline Type 5 & Initiator & $\begin{array}{l}\mathrm{NP}_{1}+\mathrm{V} 1+\mathrm{NP}_{2} \\
\mathrm{NP}_{3}+\mathrm{V} 2\end{array}$ & $\begin{array}{ll}\text { - } & \mathrm{NP}_{1} \text { : Initiator } \\
\text { - } & \mathrm{NP}_{2} \text { : Target of activity } \\
\text { - } & \mathrm{NP}_{3} \text { : Locus of affect }\end{array}$ & 3 \\
\hline Type 6 & $\begin{array}{l}\text { Target of } \\
\text { activity/ } \\
\text { Independent } \\
\text { cause }\end{array}$ & $\begin{array}{l}\text { a) } \mathrm{NP}_{2}+\mathrm{V} 1+\mathrm{NP}_{1} \\
\mathrm{NP}_{2}+\mathrm{V} 2 \\
\text { b) } \text { Covert subj }+\mathrm{V} 1+\mathrm{NP}_{1} \\
\mathrm{NP}_{2}+\mathrm{V} 2 \\
\text { c) } \mathrm{NP}_{2}+\mathrm{V} 1 \\
\mathrm{NP}_{2}+\mathrm{V} 2 \\
{ }^{*} \text { With an independent cause }\end{array}$ & $\begin{array}{l}\text { - } \mathrm{NP}_{2} \text { : Initiator (may be } \\
\text { covert) } \\
\text { - } \mathrm{NP}_{1} \text { : Target of activity } \\
\text { (may be covert) } \\
\text { (may be covert) } \\
\text { (mas affect } \\
\text { Ne Locus of }\end{array}$ & 2 \\
\hline
\end{tabular}

Table 1. Properties of Each Type of RVCs

Table 1 illustrates the properties of different types of RVCs in terms of four aspects, namely the sequence of the arguments, the argument(s) of each verb, the event roles, and the number of argument(s) of each type of RVCs. As for the event role occupying the subject position, the subject position of Type 1 to Type 5 RVCs are occupied by the initiator whereas it is the target of activity or even an independent cause that takes the subject position of Type 6 RVCs. The argument(s) of each verb shows the transitivity of each predicate. The number of NP shown in the arguments of verbs does not necessarily equal the number of event roles involved as an event role may be covert when the argument plays another event role that has a higher status in the hierarchy. Therefore, the number of arguments realized in the syntactic structure is also illustrated in Table 1.

\footnotetext{
${ }^{5}$ Independent cause refers to the cause that is neither the logical subject nor the logical object of at least one of the verbs.
} 
According to our preliminary observations, there are more constraints imposed on the use of RVCs in Cantonese, as compared to Mandarin. In the following sections, Mandarin RVCs are presented in sentence (a), and the same conceptual contents in Cantonese are demonstrated in (b) to (c), or (b) to (d). We will show how the event roles affect the grammaticality of RVCs in Cantonese, and how the same conceptual content of a Mandarin RVC is expressed when its Cantonese counterpart is considered unnatural or ungrammatical.

\section{RVCs with one argument}

As mentioned in Section 2, Type 1 is the only type that contains one argument in its syntactic structure. The example in (7) is repeated here in (16a).

(16) a. 他跑累了

tā_păo lèi le

3. $\overrightarrow{\mathrm{SG}}$ _run tired ASP

He ran himself tired.

b. 佢跑攰咗

keoi5_ paau2 gui6 zo2

3.SG_run tired ASP

He ran himself tired.

c. 佢跑到(好)攰

keoi5_paau2 dou3_(hou2) gui6

3.SG_run dou3_(very) tired

He ran himself (very) tired.

(16b) and (16c) are the possible constructions used in Cantonese to express the same conceptual base of (16a). As shown in (16a) and (16b), Type 1 RVCs can be realized using the same way in Mandarin and Cantonese. The only argument in (16) plays the initiator role and the locus of affect role, but the latter, following the Hierarchy of Event Roles proposed in Chang (2003), is not overtly expressed. The NP argument with the initiator role is put in the subject position, and thus the Linking Rule 1 is obeyed in Cantonese.

As illustrated in the V-dou3 construction used in (16c), it is also possible to insert 到 'to the extent that' in between V1 and V2. A question is raised here: are there any differences between RVC construction in (16b) and V-dou3 construction in (16c)? Most previous work on RVC construction has focused on Mandarin instead of Cantonese. Given that V-de is more frequently used than V-dao in Mandarin (Liu 2007), researchers often studied the differences between RVC construction and V-de construction instead. To demonstrate the differences between RVC construction and V-dou3 construction, we first discuss V-de and V-dao, and then compare the use of $\mathrm{V}$-de and RVC constructions. Liu (2007) suggested that V-de and Vdao have similar meanings. Wang (2008) considered both V-de and V-dao as resultative particles which can be used when the degree of the result is equal to the referential degree. Yet, if the degree value is higher than the referential degree, only the use of $\mathrm{V}$-de is licensed. Take the example given by Wang (2008: 14), 總編輯要Abi 把文章刪*得/到剩兩頁 zong bian ji yao Abi ba zhe pian wenzhang shan *de/dao sheng liang ye "The chief editor wanted Abi to cut down the content of the article to two pages". Zhou (2012) proposed that V-dao can take either a bare verb or a modal as its complement, while V-de cannot. An example taken from Zhou (2012: 148) is 李四玩到/*得累了，才回家 Lisi wan dao/*de lei le cai hui jia “Lisi did not return home until he played to the extent of being tired." The example shows that V-dao can take the bare verb 累 as its complement, but V-de cannot. This is supported in Huang (1988) 
who regarded $d e$ as an adverbial modifier or complementizer which is attached to $\mathrm{V} 1$ to introduce a resultative clause. Although V-de and V-dao may be slightly different from each other in their usage, the meaning of de and dao is similar. It is therefore inferred that the differences between $\mathrm{V}$-de and RVC is also applicable to the difference between V-dao/ V-dou 3 and RVC. Huang (1992) noted that a V-de construction takes a phrasal resultative clause while an RVC construction takes a lexical resultative clause. This is further evidenced by Cheng (2007) who claimed that a full clause can follow V-de, in which temporal adverbs and aspectual markers can be involved. Li (2002) also noticed that V-de allows temporal distance between the cause and result, while the cause and result of an RVC must be immediately contiguous.

Back to the issue of (16b) and (16c), both the V1 of the RVC and V-dou3 select a lexical resultative clause 攰 gui6 'tired'. It is suggested that there is no significant difference between the two constructions as claimed in Cheng and Sybesme (1999) and Zhang (2001) that RVC and V-dao alternate with each other. Nevertheless, Hsieh (2007) and Liu (2007) indicated that dao is used to indicate that the action or state reaches to some point. We assume that V-dou3 places greater emphasis on the action or the state reached. This also explains the reason why $\mathrm{V}$-dou 3 can take a phrasal resultative clause with $\mathrm{V} 2$ being modified by a degree adverb as in 佢跑到好攰 keoi5 pao2 dou3 hou2 gui6 'he ran to an extent that he was so tired', but RVC cannot as in *佢跑好攰 keoi5 pao2 hou2 gui6.

In (16), each verb takes only one argument and that the two arguments are referring to the same entity (i.e. 佢 keoi5 'he'). Therefore, the compound 跑攰 pao2 gui6 'run-tired' has two co-indexed arguments which play the initiator role and the locus of affect role. According to the Hierarchy of Event Role and Linking Rule 1, the initiator role takes the subject position as it has a higher status, and the locus of affect role is not overtly expressed. The presence or absence of 到 dou3 'to an extent' does not affect the position of the initiator. We claim that RVCs with only one argument are well-formed in both Mandarin and Cantonese if it is the initiator that takes the subject position. There are no syntactic differences between the RVC constructions in Mandarin and Cantonese as both of them follow the Linking Rule 1. Other examples of this type include 哭累 $k u$ lei 'cry tired', 冷醒 leng xing 'cold awake', 嚇呆 xia dai 'scared stupefy', 餓昏 $e$ hun 'starved faint', etc.

\section{$4 \quad$ RVCs with two arguments}

Type 2, Type 3, Type 4, and Type 6 contain RVCs with two arguments. Type 2 to Type 4 contain RVCs with two arguments in linear order. That is, the logical subject of V1 takes the subject position. Type 6 contains RVCs with arguments in non-linear order, which means it is the logical object that takes the subject position.

\subsection{Arguments in Linear Order}

\subsubsection{Type 2}

A Type 2 RVC is mostly composed of an intransitive V1 and an intransitive V2 ${ }^{6}$. Each verb takes an argument, referring to different entities. The subject NP of V1 is the initiator, and the subject NP of V2 (i.e. the object of the sentence) is the locus of affect of the RVC. Example (8) is repeated here in (17a).

\footnotetext{
${ }^{6}$ Some Type 2 RVCs can also be composed of a transitive V1 and an intransitive V2 on the condition that the logical object of V1 should not be overtly present in the sentence. For example, the logical object 歌 ge 'song' in 他唱哭了觀眾 ta chang ku le guan zhong 'He sang (a song) and that moved the audiences to tears.' is covert in the sentence. This kind of RVCs is different from Type 3 RVCs in terms of the presence of the target of activity role.
} 
(17)
a. 他哭煩了李四
tā kū fán le Lǐsì
3.SG_cry annoyed ASP_Lisi
He cried and it made Lisi annoyed.
b. ?佢喊煩咗李四
keoi5 haam3 faan4 zo2 Lei5sei3
3.SG cry annoyed ASP Lisi
He cried and it made Lisi annoyed.
c. 佢喊到李四好/都覺得煩
keoi5_haam3 dou3_Lei5sei3_hou2/_dou1_gok3dak1_faan4
3.SG_cry dou3 Lisi very even feel annoyed
He cried to an extent that Lisi felt very annoyed/ even Lisi felt very annoyed.
d. ?李四界佢喊煩咗
Lei5sei3_bei2_ keoi5_ haam3 faan4 zo2
Lisi_BEI_3.SG_cry annoyed ASP
Lisi was annoyed with him for crying (for a long time).

As demonstrated in (17), (17b) may not be ungrammatical to all native speakers of Cantonese, but it cannot be denied that the sentence formed with RVC construction in (17b) does not sound as natural as the one formed with V-dou3 construction as in (17c). We observed that (17b) is considered unnatural (or even ungrammatical to certain people) due to the event role of the object. In (17b), the object only plays the locus of affect role, meaning that 李四 Lei5sei3 is involved in the endpoint but he is not the entity that undergoes the crying action. In that case, the semantic relationship between 喊 haam3 'cry' and 李四 Lei5sei3 is not associated. Therefore, we stipulate that putting the argument who only plays the role of locus of affect in the object position may result in an unnatural RVC construction in Cantonese.

As for (17c), the degree adverb 好 hou ' 'very' is inserted in the sentence to modify the state denoted in V2. This is because the sentence sounds more natural to have the degree adverb modifying the state. Hence, the meaning of (17c) is slightly different from (17a) in that the intensity of the resulting state in (17c) is stronger than that of the resulting state in (17a). This is in line with Hsieh (2007) and Liu (2007)'s finding that V-dao is used to emphasize the action or the state. Apart from inserting the degree adverb 好 'very' to make the sentence a grammatical one, one may also form the sentence in 佢喊到李四都覺得煩 keoi 5 haam 3 dou 3 Lei5sei3 doul gok3dak1 faan4 'he cried to an extent that even Lisi felt very annoyed'. Xiong and Huang (2016) noticed that an adverb 都 dou3 'even' is very often present in the XP in the structure of $\left[\mathrm{NP}_{1} \mathrm{~V}\right.$-de $\left.\mathrm{NP}_{2} \mathrm{XP}\right]$. They proposed that 都 dou3 'even' is present to bring about the meaning of "unexpectedness" though not necessarily so. We suggest that the presence of 好 hou 2 'very' or 都 doul 'even' in this structure conveys the meaning that even $\mathrm{NP}_{2}$ reached such a state. The adverb is used to emphasize the action, or sometimes the state.

$(17 \mathrm{~b})$ is an active sentence, and the passive one is given in (17d). It shows that when (17b) is passivized, the passive sentence still does not sound natural to native speakers of Cantonese. Therefore, the Linking Rule 5 proposed by Chang (2003) is violated in Cantonese when dealing with Type 2 RVCs. With the locus of affect being put in the subject position and the initiator taking the object position, the sentence is still not a well-formed one.

In (17), 佢 keoi5 'he' is the initiator and 李四 'Lisi' is the locus of affect. Following the Linking Rule 1 and 2, the initiator of the Mandarin RVC in (17a) takes the subject position and the locus of affect immediately follows V2. However, Linking Rule 2 is violated in Cantonese. Different from Mandarin RVCs, putting the locus of affect role right after V2 as in (17b) does 
not sound as natural as it is in (17a). We suppose that when there are two NP arguments in an RVC construction, the sentence will be unnatural in Cantonese if the initiator takes the subject position while the locus of affect takes the object position. It is also observed that Type $2 \mathrm{RVCs}$ in Cantonese do not follow Linking Rule 2 and Linking Rule 5 as Mandarin does. This claim can be further supported by other examples of Type 2, including 跑丟 pao diu 'run lost', 哭醒 ku xing 'cry awake', 笑彎 xiao wan 'laugh bend', 走酸 zou suan 'walk tired', etc. as their Cantonese equivalents (i.e. 跑跌 paau2 dit3 'run lost', 喊醒 haam3 sing2 'cry awake', 笑彎 siu3 waanl 'laugh bend', 行攰 hang4 gui6 'walk tired') are not very acceptable in Cantonese.

\subsubsection{Type 3}

A Type 3 RVC consists of a transitive V1 and an intransitive V2, meaning that the entire RVC takes three arguments in total. Since the object NP of V1 is identical to the subject NP of V2, the event role of higher status (i.e. locus of affect) is expressed and the one of lower status (i.e. target of activity) is not. An example is shown in (9), repeated here as (18a).

(18) a. 他剪短了頭髮

tā_ jiăn duăn le _tóu fà

3.SG_cut short ASP_hair

He had a haircut.

b. 佢剪短咗頭髮

keoi5_zin2 dyun2 zo2 tau4 faat3

3.SG cut short ASP hair

He had a haircut.

c. 佢剪到啲頭髮短咗/好短

keoi5_zin2 dou3_di1_tau4 faat3_dyun2 zo2/ hou2_dyun2

3.SG_cut dou3__ POSS_hair_short ASP/ very_short

He had a haircut and his hair is shorter than he expected.

d. 啲頭髮界佢剪短咗

di1_tau4 faat3_bei2_keoi5_zin2 dyun2 zo2

POSS hair_BEI $\overline{\text { BEI }} \overline{\text { SS }}$ _ cut short ASP

His hair was cut (short) by himself.

In (18), 他/佢 ta/keoi5 'he' is the initiator and 頭髮 tou fa 'hair' is the target of activity as well as the locus of affect. The subject NP of V1 takes the subject position and the subject NP of V2 takes the object position, which is similar to (18). Why is there a restriction on the use of the Cantonese RVC in (17b), but no such kind of restriction in (18b)? The restriction is due to the event role the objects play. The object in (17b) is the locus of affect, but the one in (18b) plays both the roles of the locus of affect and the target of activity. In order words, the object 頭髮 tou fa 'hair' in (18b) underwent the action of 剪 jian 'cut' which led to a change of state in the endpoint (i.e. 頭髮短了 tou fa duan le 'hair is shortened'). However, the object 李四 Lei5sei3 in (17b) did not undergo the crying action (i.e. cannot be the target of activity). Therefore, we argue that when the subject only plays the initiator role, the object must play both the locus of affect and the target of activity in order to form a grammatical RVC construction in Cantonese as in (18). However, if the object only plays the role of the locus of affect, the $\mathrm{V}$-dou 3 construction would be preferable to the RVC construction as exemplified in (17). Type 3 RVCs shows that Linking Rule 1 is still obeyed as the initiator role should be put in the subject position. By comparing Type 2 and Type $3 \mathrm{RVCs}$, it can also be concluded that Linking Rule 2 is only applicable in Cantonese when the locus of affect also plays the role of the target of activity with the target of activity being suppressed in the sentence. 
Although (18c) illustrates that V-dou 3 construction is also possible for a Type $3 \mathrm{RVC}$, the meaning conveyed in (18b) and (18c) are different. We proposed that when a Type $3 \mathrm{RVC}$ is realized in V-dou 3 construction, the sentence implies that the state denoted in V2 is out of the speaker's expectations. For instance, the speaker of $(18 \mathrm{~b})$ simply communicates the idea that he had a haircut, but (18c) provides extra information about the result that his hair is now shorter than he expected. Again, V-dou3 in that case is used to emphasize the action 剪 jian 'cut' which was carried out to an extent that it led to an unexpected result.

(18d) demonstrates the passive construction of (18b). It is observed that the passive sentence is well-formed if the initiator is present as the object and the subject position is taken by the locus of affect which also plays the role of target of activity (suppressed in the surface structure though). Other examples of Type 3 that can be formed in both RVC construction and V-dou3 construction (with the unexpectedness reading) include 繫緊 xi jin 'tie tight', 拉長 la zhang 'elongate long', 燙直 tang zhi 'perm straight', 挖深 wa shen 'dig deep', 罵走 ma zou 'scold-go away', 咬碎 yao sui ‘bite broken', 切斷 qie duan 'cut off', 打破 da po 'break broken', 擦乾 ca gan 'wipe dry' etc.

\subsubsection{Type 4}

A Type 4 RVC is composed of a transitive V1, and a V2 that can be either a transitive or an intransitive one. If V2 is transitive, the object NP of V1 and V2 are identical, and they serve as the target of activity of the RVC. The subject NP of V1 and V2 are also referring to the same entity, one plays the initiator role and the other plays the locus of affect role. Following the Hierarchy of Event Role and the Linking Rule 1, the former is syntactically expressed in the subject position of the sentence and the latter is suppressed in the sentence. Consider (19a) and (20a), in which (19a) is a duplicate of (10).

(19) a. 他寫累了小說

tā_xiě lèi le__xiăo shuō

$3 . \overline{\mathrm{SG}}$ write tired ASP novel

He is tired for he has been writing novels.

b. *佢寫攰咗小說

keoi5_se2 gui6 zo2_ siu2 syut3

3.SG_write tired $\mathrm{ASP}$ _novel

c. 佢寫小說寫到攰

keoi5_se2_siu2 syut3_se2 dou 3 gui6

3.SG_write_novel_write dou3_tired

He is tired for he has been writing novels.

d. *小說界佢寫攰咗

siu2 syut3_BEI_keoi5_se2 gui6 zo2

novel_BEI_3.SG_write tired ASP

(20) a. 張三吃膕了海鮮

Zhāngsān_chī nì le__hăi xiān

Zhangsan_eat bored ASP_seafood

Zhangsan was tired of seafood.

b. 張三食厭咗海鮮

Zoeng1 saam1_sik6jim3 zo2_hoi2 sin1

Zhangsan eat bored ASP seafood

Zhangsan was tired of seafood. 
c. 張三食海鮮食厭咗/ 食到厭

Zoeng1saam1_sik6_hoi2 sin1_sik6 jim3 zo2/ sik6 dou3_jim3

Zhangsan_eat_seafood_eat bored ASP/eat dou3_bored

Zhangsan had seafood to an extent that he was tired of it.

d. *海鮮界張三食厭咗

hoi2 sin1_BEI_Zoeng1saam1_sik6jim3 zo2

seafood_BEI_Z Z

The difference between (19) and (20) lies in the transitivity of V2. Although the Mandarin V2 累 $l e i$ 'tired' and 膕 $n i$ 'be tired of' in sentences (a) are intransitive verbs, their Cantonese equivalents show a different property in terms of transitivity. The Cantonese counterpart of 累 lei 'tired' is 攰 gui6 'tired', which is also an intransitive verb, while 厭 jim3 'be tired of', as the Cantonese counterpart of 淢 $n i$ 'be tired of', can take an object sometimes when it functions as a verb but not an adjective. For instance, in 老年人常厭事 lao nian ren chang yan shi 'the elderly often views things in disgust' taken from a well-known Chinese writer Liang Qichao's 《少年中國說》, the verb 厭 yan 'be tired of' takes 事 shi 'things' as the object. The claim that 厭 yan 'be tired of' is a transitive verb can be further supported by the idiom 喜新厭舊 $x i$ xin yan jiu 'being fickle'. As the paper aims to investigate the grammaticality of Cantonese RVCs instead of the Mandarin ones, we consider it more appropriate to classify RVCs according to the transitivity of the Cantonese RVCs. Therefore, (19) is an example of Type 4 consisting of an intransitive V2, whereas (20) is an example of Type 4 consisting of a transitive V2. It is observed that when a Type 4 RVC is composed of a transitive V1 and an intransitive $\mathrm{V} 2$, the RVC would be formed with V-dou3 in a verb-copying construction instead of an RVC construction in Cantonese as in (19). However, if both components are transitive, there is no such restriction on the use of Cantonese RVC as in (20b).

One may notice that the V-dou3 constructions in (19c) and (20c) are not the same as those mentioned in Type 2 and Type 3. The reason for that is because the objects of (19a) and (20a) are the target of activity, but the objects of Type 2 and Type 3 RVCs are the locus of affect. According to the Linking Rule 4 in Chang (2003), a target of activity must take the position immediately following a copied verb (i.e. the first V1). Hence, V-dou3 in (19c) and (20c) have to be in a verb-copying construction. In addition, (19) can only be expressed with V-dou3 in verb-copying construction as shown in (19c), but the verb-copying construction in (20c) can be formed with either RVC or V-dou3. This is, again, due to the transitivity of V2.

(19d) and (20d) illustrate that passive RVC constructions will be ungrammatical if the subject position is taken by the NP arguments which only play the target of activity role, regardless of the transitivity of $\mathrm{V} 2$.

Back to the transitivity issue, we observed that when V2 is intransitive, a Type 4 RVC can also be realized in an RVC construction in Cantonese if the RVC takes an indefinite object or a generic NP. Chang (2003) further indicated that the Linking Rule 4 has to be obeyed unless the target of activity role is played by an indefinite object which does not have any definite references as in (21).

(21) a. 他吃飽飯了

tā_chī băo_fàn_le

3. $\overline{\mathrm{SG}}$ _eat full__

He was full after the $\overline{m e a l}$.

b. 佢食飽飯喇

keoi5_sik6 baau2_faan6_ laa3

3.SG eat full meal - SFP

He was full after the meal. 


\section{Lau and Lee}

In (21a), 飯 fan 'meal' is not used to refer to any specific food. It can only be interpreted as meal which may include various kinds of food. (21b) shows that it is also true for Cantonese. If there is an indefinite object in the sentence, the Mandarin RVC can be formed in an RVC construction in Cantonese as in (21b). Besides indefinite NPs, this is also applicable to generic NPs as in 他喝醉酒 ta he zui jiu (Mandarin)/ 佢飲醉酒 keoi5 jam2 zeoi3 zau2 (Cantonese) 'he got drunk after having a couple of drinks'. In addition to the properties of the target of activity, the transitivity of V2 also helps determine the structure in Cantonese. It is also observed that if V2 is intrinsically transitive, such as 厭 jim3 'be tired of', the compound can also be realized in an RVC construction as shown in (20b). In that case, (20c) is used to emphasize the action that had been conducted to an extent that 厭 jim3 'be tired of' was reached. Although the surface structures of all Type 4 RVCs are the same, the difference is reflected in the transitivity of V2. Type 4 RVCs with an intransitive V2 can be expressed with V-dou3 in a verb-copying construction, whereas Type 4 RVCs with a transitive V2 can be expressed with an RVC construction or with $\mathrm{RVC} / \mathrm{V}$-dou3 in a verb-copying construction using to emphasize the action. In sum, Type 4 RVCs in Cantonese follow the Linking Rule 1, with the initiators taking the subject position. Linking Rule 2 is partly obeyed. Given the objects only play the role of target of activity, Linking Rule 2 is obeyed only if both V1 and V2 per se are transitive verbs as illustrated in (20b). The RVC construction can also be formed in a verb-copying construction as in (20c). If V2 is an intransitive verb, a verb-copying construction must be used as shown in (19). It is observed that Linking Rule 4 is obeyed as the NP argument with the target of activity role immediately follows a copied verb as shown in (19c) and (20c). Other examples include 看累 kan lei 'read tired', 聽累 ting lei 'listen tired' which have an intransitive V2, and 聽怕 ting pa 'listen-sick of', 聽懂 ting dong 'listen understand' which have a transitive V2.

\subsection{Arguments with non-linear order - Type 6}

Type 6 is different from all the other types in the sequence of argument(s). The subject of each Type 6 RVC is a cause, be it dependent ${ }^{7}$ or independent. Type 6 RVCs are derived from other types of RVCs, the transitivity of V1 and V2 vary. Examples are shown in (13) - (15), repeated as in (22) - (24).

(22) a. 這部電影看哭了張三

zhè_bù__diàn yǐng_kàn kū le__Zhāngsān

this_CL_ movie_watch cry ASP_Zhangsan

Zhangsan was moved by the movie.

b. *套戲睇喊咗張三

tou3 hei3 tai2 haam3 zo2 Zoeng1saam1

$\mathrm{CL} \_$movie__watch cry ASP_Zhangsan

c. 套戲睇到張三喊

tou3_hei3_tai2 dou3_Zoeng1 saam1_haam3

CL__movie_watch dou3_Zhangsan _ cry

Zhangsan was moved by the movie.

(23) a. 這首歌唱哭了觀眾

zhè_shǒu_gē_chàng kū le_ guān zhòng

this_ $\mathrm{CL}$ _song_sing cry A $\overline{\mathrm{SP}}$ _audience

The audiences were moved by the song.

b. *首歌唱喊咗觀眾

\footnotetext{
${ }^{7}$ Dependent cause refers to the cause that is the logical subject or object of at least one of the verbs.
} 
sau2_ go1_coeng3 haam3 zo2 gun1 zung3

$\mathrm{CL}$ song _ sing cry ASP audience

c. 首歌唱到觀眾喊

sau2_go1_coeng 3 dou3__gun1 zung 3 _haam 3

$\mathrm{CL}$ _song__sing dou 3 _audience_cry

The audiences were moved by the song.

(24) a. 那個夢哭醒了張三

nà_ gè_mèng_kū xǐng le__ Zhāngsān

the_CL_dream_cry awake ASP_Zhangsan

He woke up in tears for the dream.

b. * 㧽個夢喊醒咗張三

go2__go3_mung6_ haam3 sing2 zo2__Zoeng1saam1

the CL_ dream_cry awake ASP_Zhangsan

c. *㧽個夢喊-到張三醒咗

go2__go3_mung6_ haam3 dou3_Zzoeng1 saam1_sing2 zo2

the _CL_dream_cry dou3_Zhangsan_awake $\overline{\mathrm{ASP}}$

d. 㧽個夢攪到張三喊(到)醒咗

go2_go3_mung6_gaau2 dou3_Zoenh1 saam1_haam3(dou3)__sing2 zo2

the_CL_dream_cause_Zhangsan_cry(dou3)_awake ASP

He woke up in tears for the dream.

As discussed in Section 2, Type 6 RVCs in Mandarin do not obey the linking rules proposed in Chang (2003) as other types of Mandarin RVCs do. Typical examples of Type 6 in Mandarin are shown in sentences (a) from (22) - (24). The subjects and objects of the three examples have different event roles to play. (22a) shows an RVC construction having the target of activity as the subject and the initiator and the suppressed locus of affect as the object. With the initiator being covert, (23a) presents an RVC construction having the target of activity as the subject and the locus of affect as the object. (24a) is different from the other two examples mentioned. With the initiator and the suppressed locus of affect taking the object position, the subject position in (24a) is taken by an independent cause (i.e. 那個夢 na ge meng 'the dream'), which has neither the logical object of V1 nor V2. As for sentences (b), they exemplify that all the sentences formed with Type 6 RVCs fail to form well-formed sentences regardless of the event roles subjects and objects play. As shown in the sentences (b) in this subsection, Type 6 RVCs in Mandarin cannot be realized in Cantonese with the same way. In other words, Cantonese lacks Type 6 RVCs as it does not allow non-initiators to take the subject position. Therefore, it is obvious that there is a significant difference between Cantonese and Mandarin in terms of the use of Type 6 RVCs. While Mandarin allows the target of activity or even an independent cause to take the subject position with the initiator being put in the object position, Cantonese only allows the initiator role to take the subject positions (except for RVC in bei-constructions). Most initiator roles, if not all, are the logical subject of a Cantonese/ Mandarin sentence. The reason for Cantonese lacking Type 6 RVCs may be due to the characteristics that Cantonese is a stronger VO language as compared to Mandarin. Dryer $(1992,2003)$ and Liu 劉丹青 $(2000$, 2003 ) indicated that Mandarin is unusual in its word order as it exhibits the properties of both $\mathrm{VO}$ and OV languages, meaning that Mandarin, as a SVO language, often violates the word order universals of SVO languages. This explains the why Mandarin resultative constructions with the subject position being occupied by the logical object (i.e. non-initiator) are still compatible. Liu 劉丹青 $(2000,2001)$ further examined the characteristics of Mandarin and Cantonese in terms of their word order, and suggested that Cantonese is relatively closer to the 
typical SVO/VO languages when comparing with Mandarin. In other words, Cantonese does not often violate the SVO order. Therefore, putting the logical object (i.e. non-initiator) in the subject position is rare in Cantonese. We argue that Cantonese does not allow non-canonical RVCs (i.e. Type 6) while Mandarin does is due to the stronger VO characteristics Cantonese exhibits.

As for sentences (c), they demonstrate that Type 6 RVCs can instead be formed in a Vdou 3 construction, as long as the subject is the logical object of V1. In other words, if the subject position is not occupied by an independent cause, the resultatives in (a) can be presented in the form of a V-dou3 construction as in (22c) and (23c). As the subject in (24c) is an independent cause that cannot serve as the logical object of $\mathrm{V} 1$, there is constraint imposed on the use of $\mathrm{V}-d o u 3$ construction. In that case, the RVC is formed in a causative construction with gaau2-dou3 'cause' as in (24d). The word gaau2-dou3 'cause' is used to separate the independent cause from the RVC as well as the object who is the logical subject of V1 and V2. Since the independent cause is not governed by the verbs, gaau2-dou3 'cause' introduces a finite clause which can stand alone as an independent sentence. Thus, the object 張三 'Zhangsan' in (24d) is raised to the subject position of the embedded clause preceding the two verbs. The clause introduced by gaau2-dou3 'cause' behaves just as Type 1 RVCs in that case, and therefore, the causative construction containing gaau2-dou3 can be realized in either a RVC construction (i.e. 哭喊醒 haam3 sing2 'cry awake') or a V-dou3 construction (i.e. 喊到 醒 haam 3 dou 3 sing2 'cry dou3 awake').

\section{$5 \quad$ RVCs with three arguments - Type 5}

Type 5 is the only type that contains three arguments with all the initiator, target of activity, and locus of affect roles all being present. A Type $5 \mathrm{RVC}$ must be constructed in a verb-copying construction even in Mandarin, where the target of activity can occupy the position after the copied verb. In other words, V1 of a Type 5 RVC takes two arguments and V2 takes one. An example is exemplified in (12), reproduced here as in (25a).

(25) a. 他砍樹砍斷了斧子

tā_kăn_ shù_kăn duàn le _ǔ zù

3. $\overline{\mathrm{SG}}$ _chop_tree_chop broken ASP_axe

He broke the axe accidentally while chopping down trees.

b. 佢斬樹斬斷咗把斧頭

keoi5 zaam2 syu6 zaam2 dyun6 zo2 baa2 fu2 tau2

3.SG_chop_tree_chop broken ASP_ $\overline{\mathrm{CL}}$ _axe

He broke the axe accidentally while chopping down trees.

c. 佢斬樹斬到把斧頭糹咗

keoi5_zaam2_syu6_zaam2 dou3_baa2_fu2 tau2_dyun6 zo2

3.SG_chop_tree_chop dou3_CL_axe_broken ASP

He broke the axe accidentally while chopping down trees.

(25b) and (25c) show that the RVC 砍衒 kan duan 'chop broken' can be formed with both RVC and V-dou3 in verb-copying constructions in Cantonese. The locus of affect 斧子/斧頭 $f u$ zi/fu2 tau2 'axe' in (25) is used to carry out the action denoted in V1 (i.e. 砍/斬 $\mathrm{kan} / \mathrm{zaam} 2$ 'chop') which can accidentally change its state by carrying out the action. From the initiator's viewpoint, it should be the target of activity 樹 shu 'tree' that undergoes the action and changes its state. That is, it was an accident that the locus of affect changed its state in the end. Again, $\mathrm{V}$-dou 3 in that case is to emphasize the action as well as the result. 
We observed that even if the locus of affect role is not used to carry out the action, Type 5 RVCs can still be realized with RVC and V-dou 3 in verb-copying constructions in Cantonese. Consider (26), of which (26a) is taken from Chang (2003: 329).

(26) a. 張三洗衣服洗濕了鞋子

Zhāngsān_xǐ_ yī fú_xǐ shī le_xié zǐ

Zhangsan_wash_clothes_wash wet ASP_shoe

He washed the clothes and wet the shoes by accident.

b. 張三洗衫洗濕咗對鞋

Zoeng1saam1_sai2_saam1_sai2 sap1 zo2_deoi3_haai4

Zhangsan_wash_clothes_wash wet ASP_CL_shoes

He washe $\bar{d}$ the clothes and wet the shoes by accident.

c. 張三洗衫洗到對鞋濕咗

Zoeng1 saam1_sai2_saam1_sai2 dou3_deoi3_haai4_sap1zo2

Zhangsan_wash_clothes_wash dou 3 _ $\overline{\mathrm{CL}}$ _s shoe_wet ASP

He washed the clothes and wet the shoes by accident.

Different from (25), the locus of affect 鞋子 xie zi 'shoes' in (26) is not used to carry out the action. Despite the difference, (26b) and (26c) show that the RVC 洗濕 xi shi 'wash wet' can also be formed with both RVC and V-dou3 in verb-copying constructions in Cantonese.

However, it is observed that Type 5 RVCs formed with Type 2 RVCs are incompatible with RVC in verb-copying constructions. When Type 2 RVCs which is composed of a transitive V1 and an intransitive but are unable to overtly present the logical object of V1 (i.e. target of affect) with an RVC construction are involved, the sentence cannot be formed with $\mathrm{RVC}$ in verb-copying constructions but only with $\mathrm{V}-d o u 3$ in verb-copying constructions. An example is given in (27).

（27）a． 他唱歌唱哭了觀眾

Tā_chàng_gē_chàng kū le_ guān zhòng

3.SG_sing_song_ sing cry $\overline{\mathrm{ASP}}$ _ audience

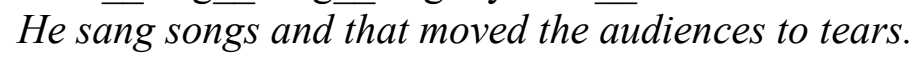

b. *佢唱歌唱喊咗觀眾

keoi5_coeng3_ go1_coeng3haam 3 zo2_ gun1 zung3

3.SG_sing_song_sing cry ASP_audience

He sang songs and that moved the audiences to tears.

c. 佢唱歌唱到觀眾喊

keoi5_coeng3_ go1_coeng3 dou3_ gun1 zung3_ haam3

3.SG_sing_song_sing dou 3 _ audience_cry

He sang songs and that moved the audiences to tears.

The RVC 唱哭 chang $k u$ 'sing cry' in (27) is a Type 2 RVC which is composed of a transitive V1 and an intransitive V2. However, it only takes 2 arguments in an RVC construction as the target of activity (i.e. logical object of V1) 歌 ge 'song' is suppressed as in 他唱哭了觀眾 $t a$ chang ku le guan zhong 'he sang (songs) and that moved the audiences to tears'. The suppressed argument 歌 ge 'song' can be presented only if we form it with verb-copying constructions in Mandarin as in (27a). However, the same construction in Cantonese does not sound as natural as it is in Mandarin. Following the properties of Type 2 RVCs, NP argument with only the locus of affect role (i.e. 觀眾 guan zhong 'audiences') cannot be linked to the position immediately following the second verb of an RVC. Thus, we assume that this is also applicable 
to RVC in verb-copying construction even if there is a target of activity 歌 ge 'song' being present and linked to the position immediately following the copied verb. The difference between (26) and (27) is that for (27), we assume that there is a suppressed target of activity 歌 ge “song' even in 他唱哭了觀眾 ta chang ku le guan zhong 'he sang (songs) and that moved the audiences to tears'. However, if we omit the target of activity 衣服 yi fu 'clothes' in (26) as in 張三洗濕了鞋子 Zhangsan xi shi le xie zi 'Zhangsan washed the shoes', we would not be able to realize that there is a suppressed target of activity, instead, we would assume that 鞋 子 xie $z i$ 'shoes' plays both the target of activity and locus of affect roles. 洗濕 $x i$ shi 'washwet' in that case belongs to Type 3. Thus, it can be concluded that a Type 5 RVC can be constructed with RVC and V-dou3 in verb-copying constructions in Cantonese, except for Type 5 RVCs formed with Type 2 RVCs, which can only be constructed with V-dou 3 in verbcopying construction.

\section{The link between classification and syntactic structure in Cantonese}

In previous sections, we have classified RVCs in terms of the number, the sequence, and the event roles of the arguments. We have showed that the use of RVC is more productive in Mandarin than it is in Cantonese. In this section, we summarize the corresponding structures used in Cantonese in forming the conceptual base of Mandarin RVCs with a table. We then discuss how the classification has contributed to the conclusion proposed in this paper. We also proposed a new set of linking rules designated for Cantonese resultatives.

In Section 3 to Section 5, it is observed that Mandarin RVCs are not often realized in the same way in Cantonese. Thus, the linking rules proposed by Chang (2003) are not often obeyed in Cantonese. Instead, there are several constructions used when Mandarin RVCs have no RVC counterparts in Cantonese, namely $\mathrm{V}$-dou 3 construction, $\mathrm{V}$-dou 3 in verb-copying construction, and causative construction with the causative verb 攪到 gaau2 dou3 'cause'. Of the three constructions, we find that V-dou 3 constructions may have three patterns in forming the conceptual content of different types of Mandarin RVCs. This is in line with Xiong and Huang (2016) who identified three types of resultative $d e$, namely unaccusative-de, causative-de, and causativized-de. As mentioned in Section 3, dou3 in Cantonese is the Mandarin equivalent for de. Therefore, $\mathrm{V}$-dou 3 constructions can also be classified into three types in Cantonese, namely unaccusative-dou3, causative-dou3 and causativized-dou3. The syntactic pattern of each type of dou3 is shown as in (28).

(28) Three types of resultative V-dou3:

a. Unaccusative $\mathrm{V}$-dou3: [NP1 $\mathrm{V} 1-$ dou $3 \mathrm{~V} 2]$

b. Causative V-dou3: [NP1 V1-dou3 $\left.\mathrm{NP}_{2} \mathrm{~V} 2\right]$

c. Causativized V-dou3: [NP1(cause) V1-dou $\left.3 \mathrm{NP}_{2} \mathrm{~V} 2\right]$

The properties of each type of RVCs and the corresponding structures in Cantonese are summarized as in Table 2. It shows that different types of Mandarin RVCs may be expressed in different syntactic structures. It is observed that RVCs can be used in Cantonese in certain conditions. The prerequisite for a resultative to be expressed in Cantonese RVCs is that the clause containing RVC has to be in linear order (except for passive constructions). That is, Cantonese RVCs can only be used when the subject is the initiator of the RVC. Given that Cantonese is one of the main varieties of Chinese, this paper adopts the linking rules proposed by Chang (2003) to explain how the position of NP arguments and the properties of the verbs in an RVC affect the grammaticality of RVC in Cantonese. The linking rules account for the position of each NP argument of Chinese RVCs. While the rules are specially designated for 
canonical sentences in Mandarin, it is observed that Cantonese obeys Linking Rule 1 even more strictly in terms of the canonicality ${ }^{8}$, as compared to Mandarin. While Linking Rule 1 is incapable of explaining the position of each NP argument of a Mandarin RVC in non-canonical sentences, it works well for the cases in Cantonese.

According to Chang's (2003) Linking Rule 1, the initiator role is linked to the subject position. However, even when the initiator role does not occupy the subject position of a Mandarin non-canonical sentence as shown in Type 6 RVCs, such a sentence containing an $\mathrm{RVC}$ is still considered grammatical. In Cantonese, all non-canonical sentences containing an $\mathrm{RVC}$ are always ungrammatical. That means, having the initiator role as the subject is the prerequisite for a RVC to be grammatically used in a sentence.

One may argue that it is also possible for Type 6-b (i.e. containing an independent cause) to be formed in RVC construction with 'gaau2-dou3' in Cantonese as shown in Table 2. According to Table 2, Type 6-b will be constructed in [ $\mathrm{NP}_{1}$ (independent cause) gaau2-dou 3 $\mathrm{NP}_{2}$ (I) V1(-dou3) V2]. The embedded clause introduced by 'gaau2-dou3' is indeed a clause that can stand alone as an independent sentence (i.e. [ $\mathrm{NP}_{2}$ (I) V1(-dou3) V2]). In that case, the subject of the RVC (i.e. $\mathrm{NP}_{2}$ ) is the initiator instead of the target of activity, meaning that the clause is in linear order which can possibly be realized in Cantonese RVC construction if it fulfils one of the following criteria.

The first criterion is that, if there is only one argument in the sentence, the subject must be the initiator and the locus of affect of that event, with the locus of affect being covert. Constructions containing Type 1 RVCs are typical examples. This also accounts for the phenomenon that Type 6-b can also be encoded with RVC in causative 'gaau2-dou3' construction. Although there are two arguments presented in the structure, the subject is an independent cause which is neither the logical object of V1 nor V2. With the help of 'gaau2dou3', the independent cause is not at the same clause level as the initiator. The initiator serves as the subject of an independent embedded clause. Therefore, the clause can simply be treated in the same way as Type 1 RVCs.

The second criterion is that, when there are two arguments in the sentence in which the subject only plays the initiator role as in Type 2 and Type 3, the object must play both the locus of affect and target of activity (suppressed in the sentence though) roles for the RVC constructions to be considered grammatical in Cantonese. This is also true for passivization of RVCs in Cantonese. Our data demonstrates that a passive RVC sentence is grammatical only if the subject position is taken by an NP argument that plays both the locus of affect and target of activity (suppressed) roles, and the object position being taken by the initiator.

The third criterion is that, when there are two arguments in which the subject plays both the initiator and locus of affect roles as in Type 4, and the object plays the role of target of activity, the grammaticality of the RVC constructions depends on the transitivity of $\mathrm{V} 2{ }^{9}$. That is, if V2 is transitive and that the target of activity can be the logical object of V2, the RVC construction is a well-formed one; if V2 is intransitive which cannot take any object, the use of RVC is prohibited.

\footnotetext{
${ }^{8}$ Canonicality concerns with the ordinary word order of a language. For example, a Chinese canonical sentence order would be: "SUBJ+ V+ (OBJ)", of which the subject is the initiator.

${ }^{9}$ By transitivity of V2, we mean the Cantonese equivalent for V2. For example, 吃淢 chi ni / 食厭 sik6 jim3 'eat be tired of' should be regarded as a Type $4 \mathrm{RVC}$ with a transitive V2 as the Cantonese equivalent for 淢 $n i$ 'be tired of' (i.e. 厭 jim3) is a transitive verb.
} 


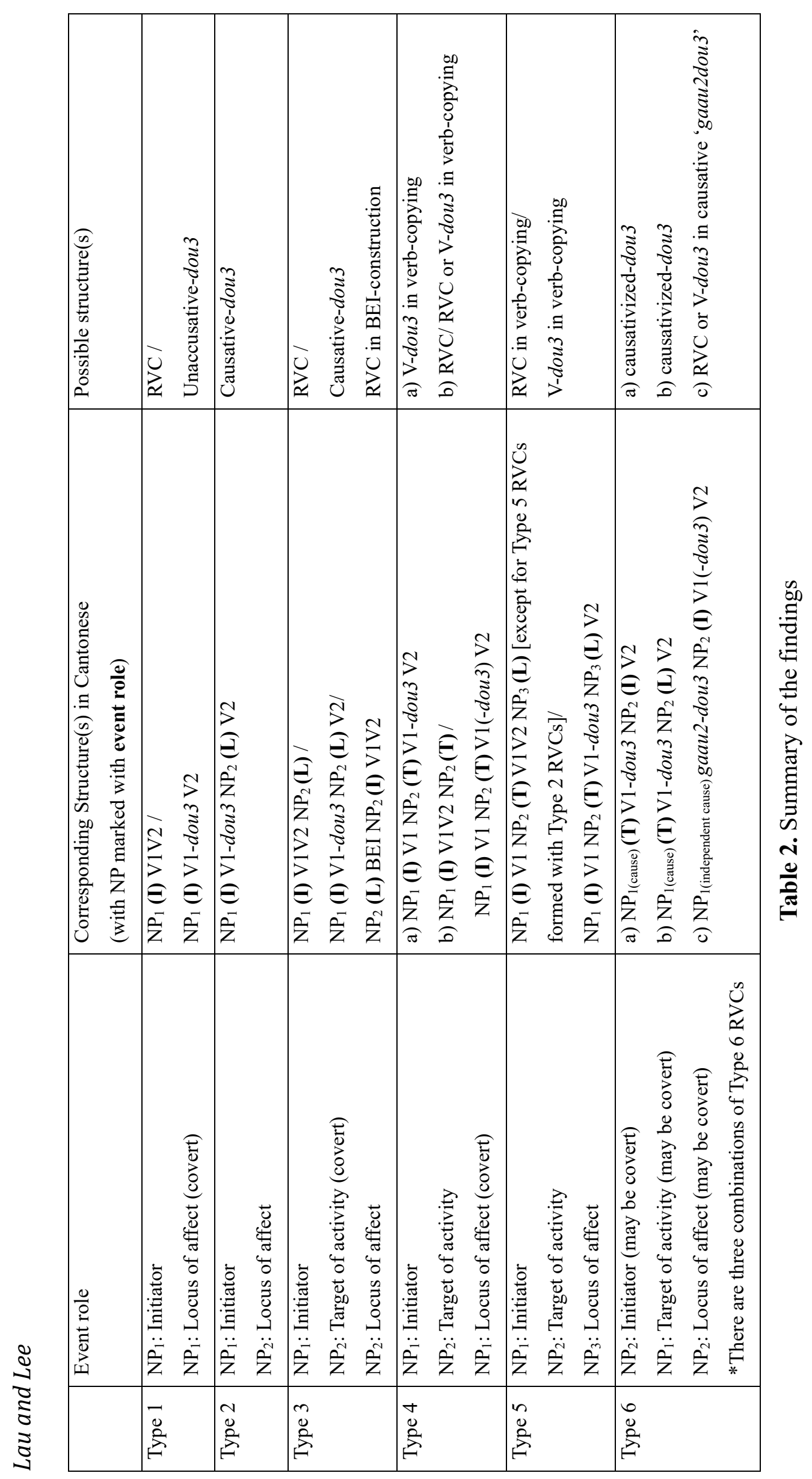


The last criterion is that, if there are three arguments expressed in the sentence, all Type 5 resultatives can be formed with RVC in verb-copying constructions in Cantonese, except for Type 5 RVCs formed with Type 2 RVCs.

This paper argues that Chang's (2003) theory is advantageous in helping us better understand the grammar of Cantonese as it is proved that it is the event role an argument plays in a resultative structure that determines how the argument is linked to the syntax. Although RVCs in Mandarin have been widely discussed by scholars (Cheng and Huang 1994, Cheng et al. 1997, Wang 2008, Gu and Yip 2004) using the generative approach, we suggest that classifying RVCs using Chang's (2003) theory of event roles, rather than the thematic roles, can better capture the differences between RVCs in Mandarin and Cantonese. From the perspective of generative linguistics, Type 2, Type 3 and Type 4 are constructions composed of an agent as the subject, a Mandarin RVC, and a theme as the object. Although the surface structures of Type 2, Type 3 and Type 4 constructions are the same in terms of the number of NP arguments and the theta-roles of these NP arguments, it is observed that some of them may be grammatically expressed in an RVC construction in Cantonese while some of them may not. However, these three types of constructions can be clearly distinguished from each other in terms of the event roles of the NP arguments, and the grammaticality of sentences containing a Cantonese RVC should be determined by these event roles. Based on Chang's (2003) theory of event roles, we propose that if the object only plays the role of locus of affect in a 2-argument RVC construction (i.e. Type 2), the same sentence expressed in Cantonese would sound unnatural to native speakers of Cantonese; if the object plays the roles of both target of activity and locus of affect in a 2-argument RVC construction (Type 3), the same sentence in Cantonese would be well-formed; and if the object only plays the role of target of activity in a 2-argument RVC construction (Type 4), the RVC construction in Cantonese would be considered grammatical only if the V2 is transitive, i.e. the object can be taken by the V2. In view of that, we propose that Chang's (2003) theory of event roles, instead of the generative approach, can better account for the grammaticality of RVC constructions in Cantonese.

As for $\mathrm{V}$-dou3 constructions, we have identified four types of $\mathrm{V}$-dou 3 that can be used to form resultatives in Cantonese, namely unaccusative-dou3, causative-dou3, causativized-dou3 and V-dou 3 in verb-copying construction. Unaccusative-dou 3 is used to form Type 1 RVCs as it is the only type that contains one argument in the syntactic structure. Causative-dou 3 is used to form Type 2 and Type 3 RVCs which have both the initiator and locus of affect being presented in the structure. Causativized-dou 3 is used to form Type 6 RVCs (excluding the subtype 6-b which has an independent cause being the subject) as the subject of a causativizeddou 3 has to be the target of activity which undergoes an action. V-dou3 in verb copying construction is used when both the initiator and the target of activity are overly expressed in the syntactic structure, regardless of the presence or absence of the locus of affect as in Type 4 and Type 5. As illustrated in Table 2, RVC constructions and V-dou 3 constructions sometimes alternate with each other. When a resultative fulfils at least one of the criteria to be encoded in an RVC construction but the speaker opts for a V-dou3 construction, the speaker is probably attempting to emphasize the action or the resulting state and to express the "unexpectedness". This can be supported by the fact that only the V-dou3 construction allows the presence of modifiers of V2, such as degree adverbs.

As for the causative construction, 'gaau2-dou3' is only used in inversed sentences (Type 6) when the subject is an independent cause and has no event roles to play. That means, when the cause (i.e. the subject of the sentence) can neither be the logical object of V1 nor V2, it should be regarded as an independent cause, and the Cantonese counterpart should be formed with 'gaau2-dou3' with either an RVC or V-dou3. This may reflect that Cantonese is more restricted on the event-role assignment issue, as compared to Mandarin. 


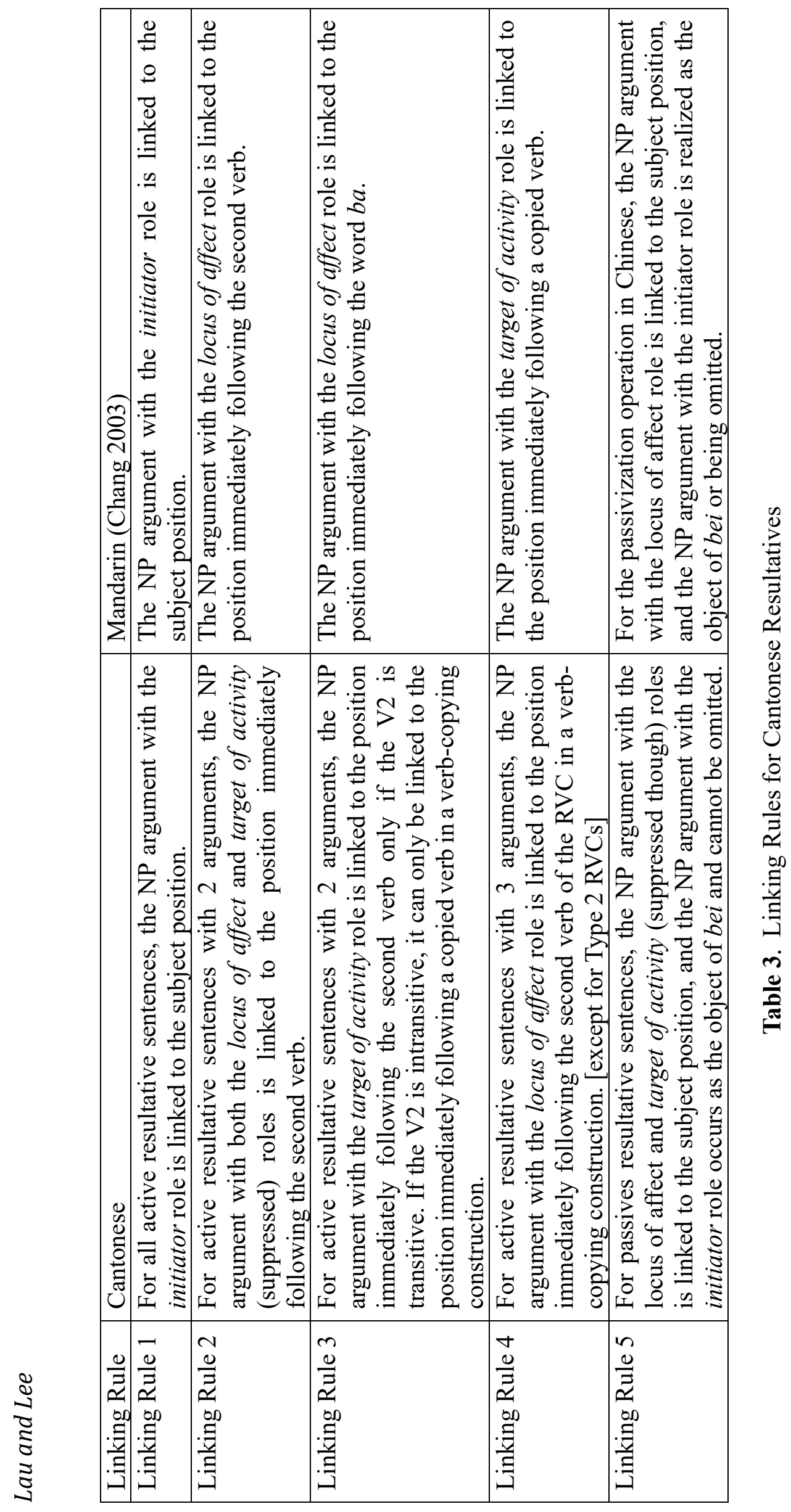


It is proved that Chang's (2003) theory of event roles is of great value for the classification of RVCs as both Cantonese and Mandarin data show that it is the event role of an argument plays in a resultative construction that determines how it is linked to the syntax. That is, the arguments of a resultative should be put in a certain position according to the event role they play. Comparing to the generative approach, Chang's (2003) theory of event roles can better classify RVCs into different types in a fine-grained way. This is especially useful when making comparisons of the same constructions between two dialects or even languages. For example, having the identical surface structure, Type 2, Type 3 and Type 4 can hardly be distinguished in terms of theta-role. However, the event roles of the NP arguments involved are completely different. This paper suggests that the three types of RVCs in Mandarin should be expressed in different ways in Cantonese. Therefore, Chang's (2003) theory of event roles, instead of the generative approach, is adopted in this paper. However, we find that the linking rules proposed by Chang (2003) can only deal with Mandarin resultatives. To cater for the Cantonese data, we propose another set of linking rules as shown in Table 3.

In this section, we have shown clearly how Chang's (2003) theory of event roles can help us better understand the grammar of Cantonese and determine the grammaticality of RVC constructions in Cantonese. We also proposed a new set of linking rules which are designated for Cantonese resultatives. It is concluded that there is a close link between this classificatory framework of RVCs and the conclusion proposed by the current work.

\section{Conclusion}

This work is concerned with issues about the expressions of resultatives in Cantonese, as compared to Mandarin. It is hoped that this piece of work sheds light on the syntax studies of Chinese Linguistics. In this final section, a brief summary of the findings will be presented.

In Section 1, we have handled the issues concerning the Mandarin and Cantonese resultative verb compounds (RVCs). The objectives of the current study were also stated. Drawing on the insight of Chang (2003) and Li (1990), we classified Mandarin RVCs into six major types in terms of the number, the sequence, and the event role of the arguments as introduced in Section 2. We have made clear how each type of RVCs differs from each other.

In Section 3 to Section 5, we have analyzed different types of RVCs and examined how these Mandarin RVCs are realized in Cantonese. It is observed that the RVC construction, Vdou 3 construction, verb-copying construction, and causative construction formed with "gaau2dou3" are the possible means in which a Cantonese resultative may be realized. Of the four constructions, verb-copying construction can be further classified into RVC in verb-copying construction and $\mathrm{V}$-dou 3 in verb-copying construction; $\mathrm{V}$-dou 3 construction can be categorized as accusative-dou3, causative-dou3, and causativized-dou3. We suggested that resultatives in Cantonese are realized in different constructions according to the event roles the involved NP arguments play.

In Section 6, we have summarized the factors that determine the constructions used in expressing Cantonese resultatives. We have also highlighted how this classification has contributed to the conclusion proposed in this paper. Furthermore, we have proposed a set of linking rules that are designated for Cantonese resultatives.

Ubiquitously found in Chinese, 'V-R compounding is a rich source of new verbs in Mandarin Chinese...' (Lin 1989). This present work is meant to provide a systematic representation of how resultatives are expressed in Cantonese to the non-native speakers of Cantonese, especially those of Mandarin-speaking backgrounds. 


\section{References}

Chang, Jung-hsing. 2001. The syntax of event structure in Chinese. Ph.D. Dissertation. Honolulu: University of Hawaii.

Chang, Jung-hsing. 2003. Event structure and argument linking in Chinese. Language and Linguistics, 4(2):317-351.

Cheng, Lai-Shen Lisa. 1997. Resultative compounds and lexical relational structures. Chinese Languages and Linguistics III: Morphology and Lexicon 167-197.

Cheng, Lai-Shen Lisa. 2007. Verb copying in Mandarin Chinese. In The Copy Theory of Movement, ed. Norbert Corver and Jairo Nunes, 107, 151-174. Amsterdam; Philadelphia: John Benjamins Pub.

Cheng, Lai-Shen Lisa, and Cheng-Teh James Huang. 1994. On the argument structure of resultative compounds. In In Honor of William S.-Y. Wang: Interdisciplinary Studies in Language and Language Change, ed. Matthew Y. Chen and Ovid J. L. Tzeng, 187-221. Taipei, Taiwan: Pyramid.

Cheng, Lai-Shen Lisa, Cheng-Teh James Huang, Yen-hui Audrey Li, and Chih-chen Jane Tang. 1997. Causative compounds across Chinese dialects: A study of Cantonese, Mandarin and Taiwanese. Chinese Languages and Linguistics 4:199-224.

Cheng, Lai-Shen Lisa, and Sybesma, Rint. 1998. On dummy objects and the transitivity of run. Linguistics in the Netherlands 15(1):81-93.

Chow, Pui-lun. 2012. The syntax-semantics Interface of resultative constructions in Mandarin Chinese and Cantonese. M.Phil Thesis, The University of Hong Kong.

Croft, William. 1998. Event structure and argument linking. In The Projection of Arguments: Lexical and Compositional Factors, ed. Miriam Butt and Wilhelm Geuder, 21-63. Stanford: CSLI Publications.

Dowty, David Roach. 1991. Thematic proto-roles and argument selection. Language 67(3): 547-619.

Dryer, Matthew S. 1992. The Greenbergian word order correlations. Language 68(1):81-138.

Dryer, Matthew S. 2003. Word order in Sino-Tibetan languages from a typological and geographical perspective. In The Sino-Tibetan languages, ed. Graham Thurgood and Randy J. LaPolla, 43-55. London: Routledge.

$\mathrm{Gu}$, Yang. 1992. The syntax of resultative and causative compounds in Chinese. Ph.D. Dissertation, Cornell University.

Hsieh, Fu-Hui. 2007. Pragmatic inferencing and sense extension of the Mandarin dao. Paper presented at the 52nd Annual Conference of the International Linguistic Association.

Huang, Cheng-Teh James. 1988. Wo pao de kuai and Chinese phrase structure. Language, 64:274-311.

Huang, Cheng-Teh James. 1992. Complex predicates in control. In Control and grammar, Richard K. Larson, Sabine Iatridou, Utpal Lahiri and James Higginbotham, 109-147. Springer Netherlands.

Huang, Chu-Ren, and Fu-Wen Lin. 1992. Composite event structure and complex predicates: A template-based approach to argument selection. In Proceedings of the $3 \mathrm{rd}$ annual meetings of the Formal Linguistics Society of Mid-America, 90-108. Northwestern University, Evanston, Illinois.

Lau, Helena Yan Ping and Sophia Yat Mei Lee. 2015. A comparative study on Mandarin and Cantonese resultative verb compounds. In Proceedings of the 29th Pacific Asia Conference on Language, Information and Computation, 231-239. Oct 30- Nov 1, 2015, Shanghai, China.

Li, Charles N. and Thompson, Sandra A. 1981. Mandarin Chinese: A functional reference grammar. Berkeley: University of California Press. 
Li, Kin-ling Michelle. 2002. On Cantonese causative constructions: Iconicity, Grammaticalization and Semantic Structures. M.Phil Thesis, The University of Hong Kong.

Li, Ya-fei. 1990. On VV compounds in Chinese. Natural Language \& Linguistic Theory, 8(2): 177-207.

Li, Ya-fei. 1995. The thematic hierarchy and causativity. Natural Language \& Linguistic Theory, 13: 255-282.

Lin, Fu-wen. 1989. The verb-complement (V-R) compounds in Mandarin Chinese. In Proceedings of ROCLING II, edited by Chu-Ren Huang and Keh-jiann Chen, 253-276. Taipei: Academia Sinica.

Liu, Danqing 劉丹青. 2000. The typological properties of Cantonese syntax 粤語句法的類型 學特點. Asia Pacific Journal of Language in Education 亞太語文教育學報 3(2):1-29.

Liu, Danqing 劉丹青. 2001. A typological comparison of word order among Chinese dialects 漢語方言的語序類型比較. Contemporary Research in Modern Chinese 現代中國語研 究 2:24-38.

Liu, Danqing 劉丹青. 2003. Word order typology and theory of adpositions 語序類型學與介 詞理論. Beijing: Commercial Press

Liu, Hsiu-Ying. 2007. The excessive structural article in Mandarin-study of dao (到). In Proceedings of the 21st Pacific Asia Conference on Language, Information and Computation, 293-302. Seoul: Seoul National University.

Lu, Hsiao-tung John. 1977. Resultative verb compounds vs. directional verb compounds in Mandarin. Journal of Chinese Linguistics 5:276-313.

O'Grady, William. 1996. The syntax files: an introductory survey of basic syntactic concepts and phenomena. Manuscript.

O'Grady, William, Michael Dobrovolsky, and Francis Katamba. (eds.) 1997. Contemporary linguistics. New York: St. Martin's Press.

Packard, Jerome L. 2000. The morphology of Chinese: a linguistic and cognitive approach. Cambridge: Cambridge University Press.

Shi, Yu-zhi. 2002. The resultative construction in modern Chinese. In The Establishment of Modern Chinese Grammar: The Formation of the Resultative Construction and its Effects (Vol. 59). Amsterdam, Philadelphia: John Benjamins Publishing.

Tai, James H-Y. 2003. Cognitive relativism: resultative construction in Chinese. Language and Linguistics 4: 301-316. Thompson, Sandra Annear. 1973. Resultative Verb Compounds in Mandarin Chinese: A Case for Lexical Rules. Language 49:361-379.

Tenny, Carol L. 1994. Aspectual roles and the syntax-semantics interface. Dordrecht: Kluwer. Thompson, Sandra Annear. 1973. Resultative verb compounds in Mandarin Chinese: A Case for Lexical Rules. Language 49:361-379.

van Voorst, Jan G. 1988. Event structure. Amsterdam: John Benjamins.

Wang, Ling-ling. 2001. A study of resultative constructions in Mandarin Chinese. Ph.D. Dissertation, The Hong Kong Polytechnic University.

Wang, Wen-Jie. 2008. Eventuality and consequence - two types of resultative verbal particles in Mandarin. MA thesis. National Jiao Tong University, Taiwan.

Williams, A. 2014. Causal VVs in Mandarin. In The Handbook of Chinese Linguistics, ed. C. T. James Huang, Y. H. Audrey Li, and Andrew Simpson, 311-341. Wiley Blackwell, Oxford.

Xiong, Jiajuan, and Chu-Ren Huang. 2016. The interaction between resultative V-de and $b a$. Paper presented at The 15th International Symposium on Chinese Languages and Linguistics (IsCLL-15), 27-29 May, 2016. Taiwan. 
Yang, Yike. 2020. Acquisition of the Mandarin $b a$-construction by Cantonese learners. Macrolinguistics 8(1):88-104.

Zhang, Niina. 2001. The structures of depictive and resultative constructions in Chinese. ZAS papers in Linguistics 22:191-221.

Zhou, Ming-Wei. 2012. The complement constructions of resultative V-de and extent V-dao in Mandarin Chinese. In Inquiries into Korean Linguistics V: Selected Works from the Eighteenth International Conference on Korean Linguistics (ICKL 18) and the Xuzhou Conference on Linguistic Sciences (2012), 133 -159. 